\title{
BMJ Open Bone mineral density, rib pain and other features of the female athlete triad in elite lightweight rowers
}

\author{
Lygeri Dimitriou, ${ }^{1}$ Richard Weiler, ${ }^{2}$ Rebecca Lloyd-Smith, ${ }^{3}$ Antony Turner, ${ }^{1}$ \\ Luke Heath, ${ }^{1}$ Nic James, ${ }^{1}$ Anna Reid ${ }^{3}$
}

To cite: Dimitriou L Weiler R, Lloyd-Smith R, et al. Bone mineral density, rib pain and other features of the female athlete triad in elite lightweight rowers. BMJ Open 2014;4:e004369. doi:10.1136/bmjopen-2013004369

- Prepublication history for this paper is available online. To view these files please visit the journal online (http://dx.doi.org/10.1136/ bmjopen-2013-004369).

Received 30 October 2013 Revised 8 January 2014 Accepted 14 January 2014

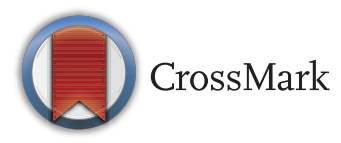

\footnotetext{
${ }^{1}$ Middlesex University, London Sport Institute, London, UK

${ }^{2}$ University College London Hospitals NHS Foundation Trust, London, UK ${ }^{3}$ University College London, London, UK
}

\section{Correspondence to} Dr Lygeri Dimitriou; I.dimitriou@mdx.ac.uk

\begin{abstract}
Objective: To determine bone mineral density (BMD) and the associations among BMD, menstrual history, disordered eating (DE), training history, intentional weight loss (IWL) and rib pain for the first time in female lightweight rowers.

Setting: 9 lightweight rowing clubs, UK. Participants: 29 Caucasian female lightweight rowers volunteered. 21 (12 active, 9 retired) completed the study. Inclusion criteria: female lightweight rowers aged over 18 years. Exclusion criteria: participants with a history of bone disease, used medications known to influence BMD or if they were pregnant, lactating or postmenopausal.

Main outcome measures: Dual-energy X-ray absorptiometry measured total body (TB) composition and BMD at the spine, femoral neck (FN), radius and TB. $\mathrm{DE}$, oligomenorrhoea/amenorrhoea years; rib pain and training history.
\end{abstract}

Results: DE was reported in six of the rowers. The active with DE started rowing younger $(p<0.05)$ than those without, and their amount of IWL was associated with Eating Attitudes Test-26 score $(p<0.05)$. Some participants reported a history of oligomenorrhoea/ amenorrhoea 17 (76\%) and/or rib pain 7 (32\%) with those with rib pain having lower spine and TB Z-scores $(p<0.05)$ than those without. Those with oligomenorrhoea/amenorrhoea had lower spine Z-scores $(p<0.01)$ than those without. Twelve participants had low BMD; three at spine; one at FN; and eight at radius. Thirteen per cent of mean total training hours $(18.6 \pm 9.1$ $\mathrm{h} /$ week) were spent strength training $(2.4 \pm 2.2 \mathrm{~h} /$ week $)$.

Conclusions: Upper body exercises incorporating multidimensional high peak bone strain were not reported and may need to be considered in their strength training to improve radial BMD. Results suggest IWL and highlevel training at a young age increases the likelihood of $\mathrm{DE}$ and there may be a lack of quality nutritional support for these athletes. Thus, multidisciplinary sport science support should be offered at a young age and perhaps also to consider changing the weight rules to prevent the development of the Triad.

\section{INTRODUCTION}

Rowing is an Olympic sport with two weight categories: open (no weight restriction) and

\section{Strengths and limitations of this study}

- The first multidisciplinary study to investigate the distribution of bone mineral density (BMD), compared to parameters established in healthy non-athletic women, in association to rib pain in UK elite active and retired female lightweight rowers.

- The first multidisciplinary study that examined BMD and total body composition via dual-energy X-ray absorptiometry, menstrual history, disordered eating, training history, intentional weight loss and rib pain in lightweight rowing which is a 'minority' sport and understudied.

- Generalisations for elite female lightweight rowers are limited by the small sample size.

- The validity of self-reported questionnaires has been critiqued on the credibility of responses.

lightweight. To qualify for racing lightweight, female rowers must weigh-in at no more than $59 \mathrm{~kg}$ with a crew average of no more than $57 \mathrm{~kg}$ (International Rowing Federation). The majority of lightweight rowers restrict their diet to meet weight restrictions using both acute and chronic methods of weight-loss. ${ }^{2}$ This could lead to disordered eating (DE), chronic energy deficiency and subsequently menstrual dysfunction and low bone mineral density (BMD).$^{3-5}$ The latter two are associated with bone stress injuries ${ }^{6}$ and endothelial dysfunction, a concern for future cardiovascular risk. ${ }^{7}$ The Female Athlete Triad (the Triad) according to the American College of Sports Medicine (ACSM) revised position statement; is an association between energy availability, menstrual function and BMD, which may have clinical manifestations including eating disorders, amenorrhoea and osteoporosis. ${ }^{5}$ Low energy availability, with or without DE, can cause amenorrhoea and reduced BMD due to reductions in leptin, ${ }^{8}$ insulin-like growth factor $1^{9}$ and oestrogen production. ${ }^{10}$ It has been reported that when severely restricted 
energy availability is prolonged, from either dietary restriction or increased expenditure, irreversible reductions in BMD could result. ${ }^{11}$ Even less severe energy restrictions could suppress bone formation and possibly prevent young women from achieving their genetic potential for peak BMD. ${ }^{11}$

The Triad is also associated with increased incidence of musculoskeletal injuries and higher stress fracture risk $^{12}$ and is prevalent in sports where leanness is considered important. ${ }^{5}$ The existence of the Triad is documented in dancers, ${ }^{13}{ }^{14}$ triathletes, ${ }^{15}$ distance runners ${ }^{16} 17$ and swimmers ${ }^{18}$ but not in female lightweight rowers, who commonly have a higher risk for rib stress fractures, ${ }^{19}$ and where leanness and weight control determine eligibility to compete and participate in the sport.

DE may describe the array of abnormal and harmful subclinical eating attitudes to lose weight or maintain low weight, and is thought to affect up to two-thirds of young female athletes. ${ }^{20}$ Sundgot-Borgen and Torstveit's, ${ }^{21}$ more recent and large study on 572 elite female athletes showed a $20 \%$ prevalence of eating disorders, indicating a significant clinical issue for the health of a great amount of athletes. Eating disorders have one of the highest mortality rates of mental illnesses, ${ }^{22}$ and have been reported to be more prevalent $(31 \%)$ in elite female athletes involved in sports emphasising leanness compared to those athletes (8\%) involved in sports with less emphasis on leanness. ${ }^{23}$ Studies on rowing have shown that lightweights are at a higher eating disorder risk than heavyweights, as identified by the Eating Attitudes Test-26 (EAT-26). ${ }^{24}{ }^{25}$ This is in accord with the higher prevalence of DE in 'weightcategory' sports which was reported by SundgotBorgen's ${ }^{26}$ study on 522 elite female athletes from 35 sports and 448 non-athletic controls. An incidence of $12 \%^{24}$ and $16.2 \%^{25}$ of DE has been reported in lightweight rowers in the past. The interlinked nature between DE, menstrual dysfunction and BMD is demonstrated in studies that established a relationship between $\mathrm{DE}$ and menstrual dysfunction, ${ }^{4}{ }^{16}$ between menstrual dysfunction and low $\mathrm{BMD}^{327}$ and between $\mathrm{DE}$ and low $\mathrm{BMD}$ in the absence of menstrual dysfunction. ${ }^{4} 1627$ Low BMD is also linked with increased incidence of stress fractures in male and female Marine recruits ${ }^{28}$ and with exercise-induced rib stress fractures in male lightweight rowers, ${ }^{29}$ Although one of the most common injuries in female rowers is rib stress fractures, its aetiology remains unclear. ${ }^{19}$ Rib stress fractures are less common in men, ${ }^{30}$ suggesting that low oestrogen levels, low BMD or factors associated with the Triad might be causative for rib stress fractures in female rowers.

To date, no studies have investigated BMD in relation to rib stress fractures in female lightweight rowers. This reinforces the view ${ }^{31}$ that the pathology and prevention of rib stress fractures is a worthy area of research in rowing. Little is known about the possible long-term implications of the Triad but it appears that the effects on BMD might be partially irreversible. ${ }^{13} 3233$
The aims of the present study were therefore to investigate: (1) the distribution of BMD for the first time in UK elite active and retired female lightweight rowers compared to the parameters established in healthy nonathletic women; (2) the associations among BMD, menstrual history, training history, DE, intentional weight loss (IWL) and rib pain and (3) assess whether any past DE symptoms and menstrual dysfunction continue after retirement.

\section{METHODS}

\section{Ethics}

This research received no specific grant from any funding agency in the public, commercial or not-forprofit sectors. Details of the study's aims, methods and testing procedures were explained to each participant, before a written, informed consent was obtained.

\section{Participants}

Participants were recruited from responses to recruitment advertisements for current and retired lightweight rowers offering free determination of BMD and total body (TB) composition in rowing clubs and a rowing magazine. No mention of DE, menstrual disorders and other aspects of the Triad were included in the advert to avoid possible sample selection bias. The year of this study only 79 UK female lightweight rowers were identified to participate in national and international level competitions. Twenty-nine Caucasian female lightweight rowers, from nine different clubs volunteered to participate in this study. Only 21 (12 active, 9 retired) met the study's criteria and volunteered for the study. Inclusion criteria were females aged over 18 years who had rowed competitively in lightweight category for no less than 1 year. Participants were excluded if they had a history of bone disease, used medications known to influence BMD (eg, corticosteroids, antidepressants, thiazolidinediones, bisphosphonates, non-steroidal anti-inflammatory drugs and chemotherapy) or if they were pregnant, lactating or postmenopausal. Two rowers were excluded and six withdrew for logistic reasons. Rowing competition level was: 5 international (2 active) and 16 national (10 active) levels. All were non-smokers and their mean weekly alcohol consumption was $5.8 \pm 1.2$ units/week. None reported vitamin $\mathrm{D}$ and calcium supplements intake and all but two did not regularly (3-4/week) eat products containing calcium.

\section{QUESTIONNAIRES}

\section{EAT-26 and pathogenic weight control strategies}

Symptoms and characteristics of eating disorders were assessed by the EAT-26, a 26-item inventory with strong psychometric properties. ${ }^{34}$ Thirteen items relate to 'dieting' behaviour, six to 'Bulimia and Food Preoccupation' and seven to 'Oral Control'. The 26 items of the EAT-26 inventory were rated on a six-point response scale as described in Garner et al. ${ }^{34}$ The score 
can range from $0-78$. A score of 20 or above is considered indicative of $\mathrm{DE} .{ }^{34}$

Self-reported questionnaires assessed whether participants had been engaged in any pathogenic weight control strategies such as vomiting and/or use of laxatives to induce weight loss within the past 6 months. Present or past engagement in binge eating behaviour, eating more than other people would in the same situation $^{35}$ and whether they had previously been diagnosed with an eating disorder were also assessed. Retired rowers were assessed to observe whether any past pathogenic weight control strategies continued after retirement.

\section{Menstrual history questionnaire}

All rowers reported their age of menarche and number of menses for each year after menarche choosing from the following options: amenorrhoea (0-3), oligomenorrhoea (4-9) and eumenorrhoea (10-13). ${ }^{16}$ Total lifetime menses (years) and number of years of amenorrhoea and oligomenorrhoea was calculated as described in Cobb et $a l^{16}$ and normalised for age by dividing the number of years of each of the above menstrual variables with current age. Owing to the small sample size, menstrual history status was categorised into two groups of oligomenorrhoeic/amenorrhoeic (those with history of oligomenorrhoea/amenorrhoea) and eumenorrhoeic (those without). Retired rowers were assessed to observe whether any history of oligomenorrhoea/amenorrhoea continued after retirement.

\section{Additional questionnaires}

Self-reported questionnaires assessed demographic data, including details of sporting history, mode of training including type of resistance training exercises and average weekly training volume (hours) at highest competitive level for both retired and active rowers, level of competition, medical history, use of medications, supplements and oral contraceptives (OCAs), smoking, alcohol intake and weight loss. Duration of OCA use was normalised for gynaecological age by dividing the number of years of OCA use with gynaecological age. History of injury was reported by drawing the area of symptoms on a body chart and answering questions about cause of injury, duration of symptoms and diagnosis. History, duration and cause of rib pain were also recorded. Participants were also asked whether they had ever been provided with nutritional and/or weight management advice from coach/club. Retired rowers gave details of physical activity since retiring from lightweight rowing. Questionnaire details were verbally explained to each participant in conjunction with written instructions. While participants were completing the questionnaires investigators were present to clarify any issues/questions and tried to ensure that the answers were as accurate as possible.
Physical and bone measurements

$\operatorname{BMD}\left(\mathrm{g} / \mathrm{cm}^{2}\right)$ at the posteroanterior (PA) L2-4 lumbar spine (LS); PA femoral neck (FN); dominant arm distal radius; TB and body composition (lean and fat mass) were measured by dual-energy X-ray absorptiometry (fan beam, Lunar DPX-L series GE Medical systems, Lunar Madison, Wisconsin, USA). The in-house coefficient of variation of the BMD measurements ranged from $0.5-1.4 \%$. The scanner was calibrated using a spine phantom at the start of each day of testing and its performance was followed with the labs quality assurance protocol. Z-scores were calculated using the manufacturer-supplied reference data (Lunar enCORE USA/European reference data) set to compare individuals BMD values to age and sex-matched controls. The ACSM defines the term 'low BMD' as a Z-score between -1 and -2 , and 'osteoporosis' a Z-score $\leq-2$ together with secondary risk factors for fracture (eg, chronic malnutrition, eating disorders, hypoestrogenism, hypogonadism, glucocorticoid exposure and previous fractures ${ }^{3}$ ).

All participants were requested to refrain from heavy physical activity $24 \mathrm{~h}$ before screening to minimise the effect of fluctuations in hydration status on body composition measurements. Participants' height $(\mathrm{m})$ and body mass $(\mathrm{kg})$ were measured using standard stadiometers and balance beam scales, respectively. Body mass index (BMI) was calculated as $\mathrm{kg} / \mathrm{m}^{2}$. All anthropometric measurements, scanning and analyses were performed by the same technician using the same equipment.

\section{Statistical analyses}

Statistical analyses were performed using SPSS V.16.0. Values are reported as means \pm SD. Statistical significance was set at $\mathrm{p}<0.05$. Levene's test was used to assess equality of variances in the different groups. Violations of the equality of variances assumption were corrected using the $p$ value calculated for equal variances not assumed. A General Linear Model was used to determine whether Z-scores, years of training, age of menarche and amount of IWL differ: (1) between rowers with and without history of oligomenorrhoea/amenorrhoea or rib pain and (2) between active rowers that scored $\geq 20$ and active rowers that scored $<20$ on the EAT-26. When the Z-scores were analysed to assess for differences between participants, data were adjusted/controlled for BMI, ${ }^{36}$ by fitting an analysis of covariance to the data.

Z-scores were used in the statistical analyses, as they are normative values for chronological age. Pearson's correlation coefficient was used to determine significant relationships between variables of interest. Any analysis performed between Z-scores and other specific variables was controlled for BMI. Correlation analysis between EAT-26 score and amount of IWL and duration of OCA use was applied only in the data of active rowers. The retired were excluded because their weight loss data refers to the past while the EAT-26 data refers to their current DE attitudes. 


\section{RESULTS}

The anthropometric characteristics, training and menstrual history details and OCA use of the lightweight rowers is summarised in table 1 .

\section{Bone mineral density}

Three participants had low BMD at LS (Z-scores -1.5, -1.2 and -1.1), one at FN (Z-score -1.1) and eight at radius. Three of these had Z-scores below -2 at radius (Z-scores -2.3, -2.1 and --2.3). As depicted in figure 1, the mean Z-scores of the oligomenorrhoeic/amenorrhoeic, active and retired rowers was significantly lower at $\mathrm{LS}\left(\mathrm{AD}=1.75, \mathrm{~F}(2.21)=11.455, \mathrm{p}<0.01, \eta \mathrm{p}^{2}=0.560\right)$ compared to the eumenorrhoeic rowers. Total lifetime menses (controlled for BMI values) was positively associated with Z-scores at LS $(\mathrm{r}=0.516, \mathrm{p}<0.05)$ and at FN $(\mathrm{r}=0.438, \mathrm{p}<0.05)$.

Furthermore, when the retired were looked at separately, the results revealed that the oligomenorrhoeic/ amenorrhoeic rowers had significantly lower Z-scores at LS $\left(\mathrm{AD}=2.7, \mathrm{~F}(2.9)=17.307, \mathrm{p}<0.01, \eta \mathrm{p}^{2}=0.852\right)$ and $\mathrm{TB}$ $\left(\mathrm{AD}=1.47, \mathrm{~F}(2.9)=26.756, \mathrm{p}<0.01, \eta \mathrm{p}^{2}=0.899\right)$ compared to the eumenorrhoeic retired rowers. Mean Z-scores of eumenorrhoeic retired were above normal at all sites.

Disordered eating, pathogenic weight control strategies All active rowers reported engagement in IWL to qualify for lightweight racing. Both active and retired rowers
Rowers without oligo/amenorrhea

Rowers with oligo/amenorrhea

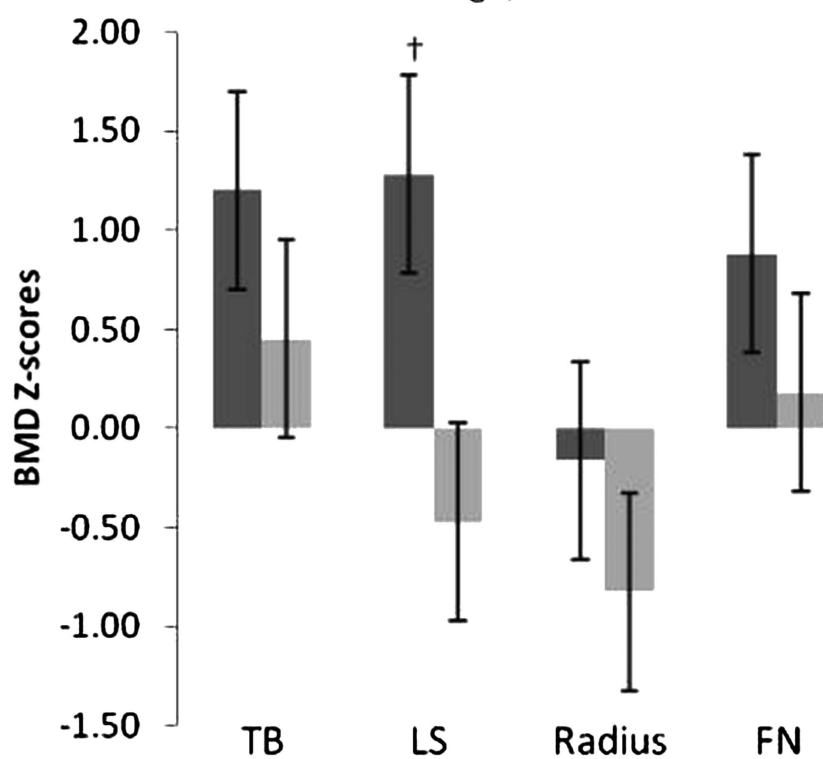

Figure 1 BMD Z-scores (mean $\pm S D$ ) at TB, LS, radius and NF in rowers with and without a history of oligomenorrhoea/ amenorrhoea. †Significant difference $(p<0.001)$ between rowers with and without a history of oligomenorrhoea/ amenorrhoea. BMD, bone mineral density; LS, lumbar spine; NF, neck of femur; TB, total body.

Table 1 Anthropometric characteristics, training and menstrual history details and OCA use of lightweight rowers

\begin{tabular}{|c|c|c|c|}
\hline Variable & $\begin{array}{l}\text { Active } \\
\mathrm{N}=12\end{array}$ & $\begin{array}{l}\text { Retired } \\
\mathrm{N}=9\end{array}$ & $\begin{array}{l}\text { Both } \\
\mathrm{N}=21\end{array}$ \\
\hline Age (years) & $26.6 \pm 2.0$ & $31.6 \pm 5.0$ & $28.7 \pm 4.3(23-39)^{*}$ \\
\hline Stature $(\mathrm{cm})$ & $171.8 \pm 5.5$ & $165.7 \pm 2.8$ & $169.2 \pm 5.4(162.0-179.5)$ \\
\hline Body mass $(\mathrm{kg})$ & $61.2 \pm 1.8$ & $61.5 \pm 5.4$ & $61.3 \pm 3.7(56.8-73)$ \\
\hline Body fat $(\%)$ & $21.4 \pm 5.8$ & $23.1 \pm 7.2$ & $22.1 \pm 6.4(11.6-35.1)$ \\
\hline BMI $\left(\mathrm{kg} / \mathrm{m}^{2}\right)$ & $20.8 \pm 1.1$ & $22.3 \pm 2.6$ & $21.4 \pm 2.0(19.5-27.8)$ \\
\hline Age at onset of exercising (years) & $15.1 \pm 5.7$ & $11.3 \pm 4.6$ & $13.5 \pm 5.6(4-26)$ \\
\hline Years playing sports & $11.5 \pm 5.2$ & $20.2 \pm 5.0$ & $15.2 \pm 6.7(2-31)^{*}$ \\
\hline Years training at lightweight category & $2.5 \pm 1.1$ & $6.0 \pm 3.8$ & $4.0 \pm 3.1(1-12)^{*}$ \\
\hline Training per week $(\mathrm{h}) \dagger$ & $15.3 \pm 4.1$ & $22.9 \pm 12$ & $18.6 \pm 9.0(10-53)$ \\
\hline Strength and power training per week $(h) \dagger$ & $1.7 \pm 1.6$ & $3.3 \pm 2.6$ & $2.4 \pm 2.2(0-10)$ \\
\hline Water rower training per week $(\mathrm{h}) \dagger$ & $8.8 \pm 2.8$ & $11.1 \pm 2.7$ & $9.8 \pm 3.0(5-16)$ \\
\hline Cardiovascular training (cycling, running, ergometer rowing) per week $(\mathrm{h}) \dagger$ & $4.8 \pm 2.2$ & $8.6 \pm 9.8$ & $6.4 \pm 6.7(1-33.5)$ \\
\hline Age at onset of retirement (years) & NA & $28.6 \pm 5.6$ & NA \\
\hline Years since retirement & NA & $3.0 \pm 1.9$ & NA \\
\hline OCA (years) & $4.3 \pm 3.1$ & $2.4 \pm 1.4$ & $3.9 \pm 2.7(1-9)$ \\
\hline Years with oligomenorrhoea/amenorrhoea & $4.5 \pm 3.9$ & $4.2 \pm 4.4$ & $4.4 \pm 4.0(0-13)$ \\
\hline Menarcheal age (years) & $13.4 \pm 1.1$ & $13.0 \pm 1.2$ & $13.2 \pm 1.1(11-15)$ \\
\hline Oligomenorrhoeic/amenorrhoeic (N) & 10 & 7 & 17 \\
\hline Gynaecological age (years) & $13.2 \pm 2.2$ & $18.5 \pm 5.1$ & $15.5 \pm 4.5(10-27)^{*}$ \\
\hline Total lifetime menses (years) & $10.8 \pm 2.3$ & $14.6 \pm 5.4$ & $12.4 \pm 4.3(4.9-25.3)$ \\
\hline
\end{tabular}


Table 2 Reported eating attitudes in lightweight rowers

\begin{tabular}{|c|c|c|c|}
\hline & $\begin{array}{l}\text { Active } \\
\mathrm{N}=12\end{array}$ & $\begin{array}{l}\text { Retired } \\
\mathrm{N}=9\end{array}$ & $\begin{array}{l}\text { Overall } \\
\mathrm{N}=21\end{array}$ \\
\hline DE symptoms, N (\%) & $5(42)$ & $1(11)$ & $6(29)$ \\
\hline Binge eating episodes, N (\%) & $8(67)^{*}$ & $0^{*} \dagger$ & $8(38)$ \\
\hline Induced vomiting, N (\%) & $3(25)^{*}$ & $0^{\star} \dagger$ & $3(14)$ \\
\hline Use of laxatives, N (\%) & $4(33)^{\star}$ & $\begin{array}{l}0^{*} \\
2(22) \dagger\end{array}$ & $6(29)$ \\
\hline Intentional weight loss, N (\%; mean loss SD) & $12(100 ; 5.8 \pm 1.9 \mathrm{~kg})$ & $8(89 ; 6.3 \pm 4.5 \mathrm{~kg}) \ddagger$ & $20(95 ; 6.0 \pm 3.2 \mathrm{~kg})$ \\
\hline
\end{tabular}

${ }^{*}$ Within the past 6 months.

†Past reported symptoms during their rowing career.

$\ddagger$ Past intentional weight loss to qualify for racing lightweight during their rowing career.

$\mathrm{DE}$, disordered eating.

reported DE attitudes (EAT-26 score $>20$ ) and pathogenic weight control strategies (table 2).

Independent sample $t$ tests showed that active rowers with DE symptoms, had started rowing at a significantly younger age (10.6 \pm 3.1 years) than those without $\mathrm{DE}$ $(18.3 \pm 4.9$ years; $\mathrm{t}=-3.088, \mathrm{p}<0.05)$. The EAT-26 score was associated with the amount of IWL $(r=0.720, p<0.05)$, see figure 2, and duration of OCA use $(r=0.908$, $\mathrm{p}<0.001)$.

\section{Rib pain}

Seven participants (32\%) reported a history of rib pain lasting between 2 and 10 weeks. As depicted in figure 3, the Z-scores at TB and LS were significantly lower $(\mathrm{p}<0.05)$ in rowers with history of rib pain compared to those without. Additionally, rowers with rib pain reported to train more hours per week, (21 vs $17 \mathrm{~h}$, $\mathrm{p}>0.05)$, and to have higher oligomenorrhoea/amenorrhoea years ( 8.8 vs 4 years, $\mathrm{p}>0.05$ ) than those without.

\section{DISCUSSION}

This study confirms the coexistence of reduced BMD, oligomenorrhoea/amenorrhoea, DE and IWL, in UK elite female lightweight rowers. The association between total lifetime menses and BMD supports the notion that

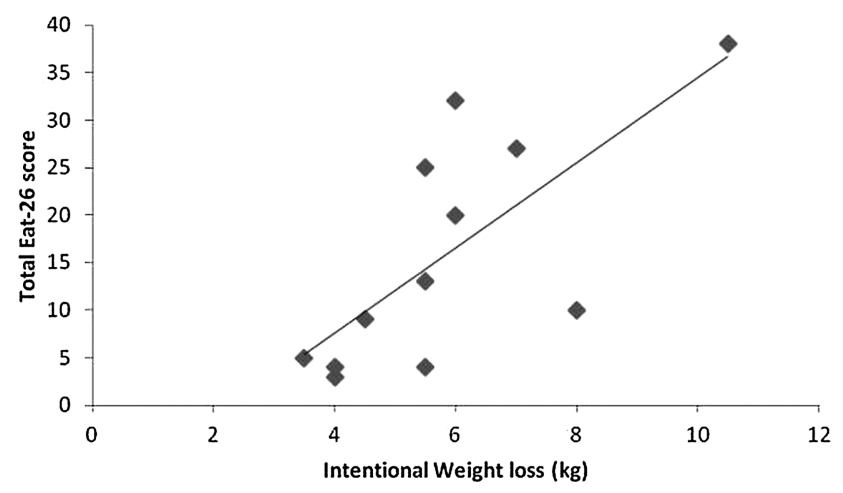

Figure 2 Relationship between the amount of intentional weight loss and EAT-26 score, a measure of DE, in active rowers, $(r=0.720, p<0.05)$. DE, disordered eating; EAT-26, Eating Attitudes Test-26.
BMD declines as the number of missed menstrual cycles accumulate. $^{32}$

A novel, but concerning finding in this study was that total EAT-26 score was associated with the amount of IWL in active rowers which suggests that IWL increases the likelihood of engaging in DE behaviours. Furthermore, active rowers with DE symptoms, had started rowing at a significantly younger age (10.6 \pm 3.1 years) than those without DE ( $18.3 \pm 4.9$ years), which suggests involvement in high level training at a young and vulnerable age (all rowers achieved national and international level) is significantly associated with risk to DE attitudes. ${ }^{37} \mathrm{~A}$ meta-analysis of 34 studies (2459 athletes) supports these findings, which showed an increased risk of DE in elite athletes compared to

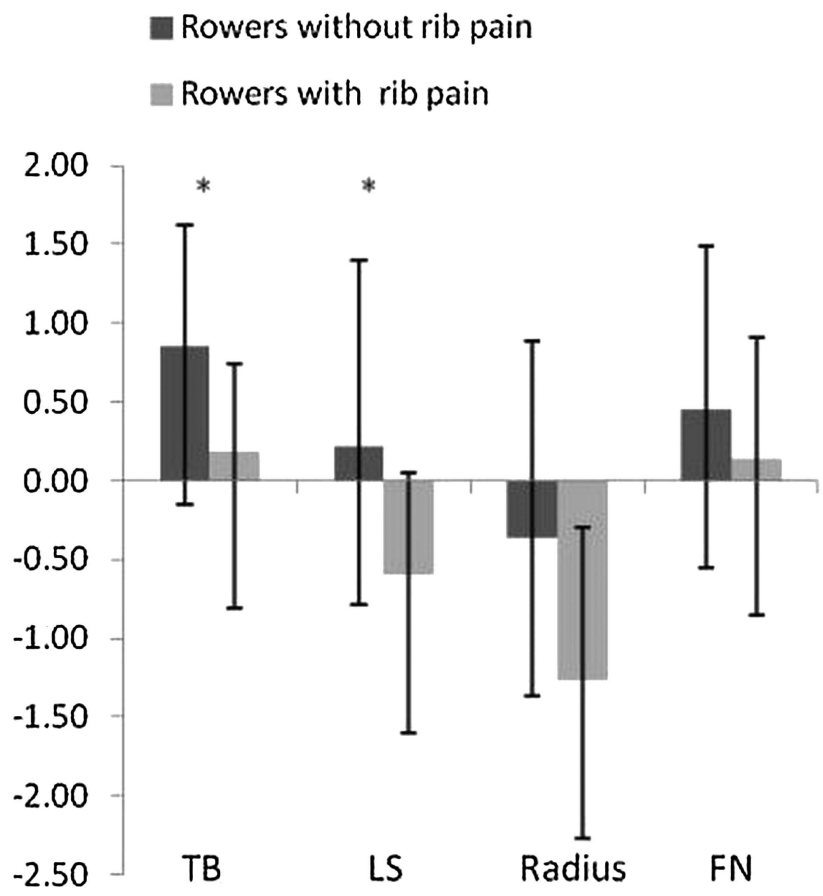

Figure 3 BMD Z-scores (mean $\pm S D$ ) at TB, LS, radius and $\mathrm{NF}$ in rowers with and without a history of rib pain. *Significant difference $(p<0.05)$ between rowers with and without a history of rib pain. BMD, bone mineral density; LS, lumbar spine; NF, neck of femur; TB, total body. 
non-elite. ${ }^{38}$ Additionally, a higher prevalence of eating disorders among adolescent elite athletes than controls has been reported in a most recent study by Martinsen and Sundgot-Borgen. ${ }^{39}$ Binge eating was also a common finding among the active rowers $(67 \%)$, which compares to $52 \%$ encountered by Thiel $e t a l^{40}$ Pathogenic weight control strategies and symptoms of DE and binge eating were more prevalent in the active than the retired rowers of this study, and in earlier studies on elite rowers. ${ }^{24} 25$

Furthermore, only 2/12 (17\%) active compared to $4 / 9(44 \%)$ retired were reported to have received professional nutritional support for rowing and weight management. The importance of nutritional guidance to help in the prevention and treatment of DE has been evident to this study and is in agreement with Beals and Manore, ${ }^{41}$ who stated that one of the issues that leads athletes to fail to meet their exercise energy requirements is lack of appropriate nutritional knowledge. Sundgot-Burgen and Klungland, ${ }^{42}$ reported that the prevalence of $\mathrm{DE}$ was reduced from $33 \%$ to $15 \%$ in cross-country skiers over an 8-year DE preventative programme. Therefore, quality nutritional guidance should be offered from a young age to possibly minimise DE and the health related risks. ${ }^{4} 16{ }^{43}$ Youth rowing coach education on DE and Triad risk or perhaps even weight category rule change consideration may also be needed to prevent DE, the Triad and associated unhealthy conditions in developing lightweight female rowers.

Weight loss is predominantly the result of negative energy balance, however, methods of IWL such as the use of laxatives, which was reported in this study, or other dehydration methods do not necessarily mean low energy availability ${ }^{44}$ or a symptom of DE. In this study no association was found between symptoms of DE and $\mathrm{BMD}$, which is contrary to previous studies. ${ }^{4}{ }^{16}$ However, these studies determined energy deficiency, and assessed DE with the Eating Disorder Inventory instead. Possibly, $\mathrm{DE}$ is not necessarily a component of the Triad whereas low energy availability is. ${ }^{5}$ Assessment of DE is also an important medical consideration, and can help identify psychopathological individuals with the Triad, in addition to indirectly establishing the possibility of low energy availability.

Prevalence of DE in lightweight rowers, as assessed by a score $\geq 20$ on the EAT-26 questionnaire, has been reported to be between 12 and $16 \%{ }^{24}$ compared to $29 \%$ in this study. These results suggest that the rowers from the above research studies and the present study are considered 'at risk' for clinical eating disorders. ${ }^{45}$ This percentage could have been even higher as athletes tend to under report symptoms of $\mathrm{DE}^{2026}$ due to denial and secrecy which are hallmarks of $\mathrm{DE},{ }^{22}$ and because they do not consider eating habits as DE, but as 'part of the game' in season. Denying DE symptoms has clinical implications for these athletes including delayed facilitation of appropriate therapy. Furthermore, the validity of self-reported questionnaires has been critiqued on the credibility of honest responses. Therefore, the use of questionnaires alone to assess symptoms of $\mathrm{DE}$ would be best if complemented with a clinical interview in future studies.

In ballet dancers and runners, the reproductive hormonal changes caused by excessive exercise and low energy availability may result in low BMD at LS. ${ }^{16} 46$ The mechanical stresses of rowing appear to exert protection on the lumbar BMD. ${ }^{47}$ The eumenorrhoeic rowers in this study demonstrated elevated BMD measurements compared to their age and sex-matched reference data, particularly at LS, which is in accord with Wolman et $a l^{48}$ However, the mean lumbar BMD of the oligomenorrhoeic/amenorrhoeic rowers in this study was not elevated compared to their age and sex-matched reference data, suggesting that oligomenorrhoea/amenorrhoea has a negative effect on BMD. ${ }^{32}$ This can be further supported by the significantly lower Z-score observed at LS in the rowers with history of oligomenorrhoea/amenorrhoea compared to those without, and the positive association between total lifetime menses and Z-scores at LS and FN found in this study. Previous studies have shown similar findings. ${ }^{4} 46$

In line with the practices of coaches working with rowers in Great Britain, ${ }^{49}$ the rowers in this study engaged in strength and power training, predominately consisting of squats, cleans and lower-body plyometrics. The nature of the sport, and the direction of force application, dictates that these pulling movements and closed chain exercises are indeed rational and explains their routine recommendation. ${ }^{50}$ Specifically, Ebben et a $\tilde{\rho}^{1}$ reported that an 8-week strength and power programme using these, improved time, power and power per stroke during $2000 \mathrm{~m}$ ergometer rowing. Unsurprisingly, pushing based strength exercises for the upper body, such as the bench press, rank quite low on importance, and upper-body plyometrics generally do not feature. ${ }^{49}$ From a training specificity and performance-based point of view, the reasons for this appear sound. However, of a bone health perspective, such a focused approach may be contested. The results of this study and that of others ${ }^{17} 52$ have reported low BMD in the radius of athletes, suggesting that current training paradigms may not address this appropriately and perhaps fitness coaches should also address the current and future health of their athletes. At times, this will require a nonsport specific approach.

Furthermore, to support bone health, general health, injury prevention and sporting performance, current training paradigms should be supported with effective nutritional guidance and psychological support, when required, to educate, prevent, recognise, support and manage weight loss and DE in lightweight female rowers. $^{53}$

Specifically, in this study eight rowers had low BMD at the radius $(\mathrm{Z}<-1)$ and it has been recommended that a Z-score of $<-1.0$ in an athlete warrants further clinical investigation and management, even in the absence of 
prior fracture. ${ }^{5}$ The marked incidence of low BMD at radius might suggest that the stress applied on the upper limb skeleton through joint-reaction forces, generated during the rowing and/or the strength and power training undertaken by the rowers in this study were not sufficient to elicit an increase in BMD or maintain it to normal physiological levels. ${ }^{54}$ It might also suggest that these tensile forces were insufficient to counteract the negative effects of low energy availability on $\mathrm{BMD}^{3-5}{ }^{11}$ possibly induced by IWL methods, a common practice in lightweight rowers as seen here and in previous research. ${ }^{1}{ }^{36}$ Furthermore, low radius BMD might reflect the dissipation/diversion of BMD to weight-bearing sites, at the expense of non-weight bearing sites, such as the radius. ${ }^{52}$ These findings reinforce the tenet that bone mineral acquisition obeys a principle of specificity ${ }^{52} 55$ and that the effects of joint reaction forces on bone formation are not as effective as those observed through ground reaction forces generated during dynamic sports and/or activities like running, jumping, kicking, tennis, punching and plyometrics which can incorporate multidimensional (non-conventional) high peak loading compressing strains distribution into the bone. ${ }^{54-56}$

In summary, exercises that directly target the arms such as the bench press and plyometric push-ups may help in the modelling/remodelling of the bone. This comes into contrast with the sport-specificity theorem and the authors of this study strongly recommend the implementation of supplemental non-sport specific exercises in the training programmes of rowers and other athletes, that particularly suffer from low radius BMD, could be a promising means of maximising bone accrual and health, and possibly reducing the incidence of skeletal fractures later in life. This is the first study that contrasts with the sport-specificity theorem.

Little is known about the long-term effects of DE and oligomenorrhoea/amenorrhoea on BMD. In retired rowers with a history of oligomenorrhoea/amenorrhoea, despite resuming normal menses, their Z-scores at LS and TB were significantly lower than those who had always been eumenorrhoeic. This corroborates the existing body of knowledge, which suggests that deficits in BMD may be irreversible. ${ }^{13} 3233$ Longitudinal study on a higher number of female lightweight rowers is required to understand this issue more adequately.

An incidence of rib stress fractures in male rowers of up to $12 \%$ has been reported. ${ }^{29}$ Seven $(32 \%)$ of the participants in this study had history of rib pain lasting 28 weeks ( $5.1 \pm 2.9$ weeks). While these participants had no radiographic evidence to confirm diagnosis of rib stress fracture, our study suggests the incidence of rib pain is a common discomfort in female lightweight rowers (2.7 times more common than male rowers) and chronic chest wall pain in rowers is almost always the result of rib stress fractures as suggested by Strayer ${ }^{57}$ However, a subsequent study reported that athletes tend to self-report a higher percentage on stress fractures $(14 \%)$ compared to those diagnosed with stress fractures $(8.1 \% ; \mathrm{p}<0.001)$, indicating that self-reporting of stress fractures has low validity. ${ }^{58}$ Owing to the retrospective nature of this study in terms of assessing rib stress fractures incidence, it was not possible to make a clinical diagnosis. In this study active and retired rowers with history of rib pain had significantly lower LS and TB Z-score values than those without history, which possibly suggests that low BMD may play a role in the aetiology of exercise-induced rib stress fractures in female lightweight rowers. Interestingly, Nevill et a $\bar{l}^{\tilde{p}^{2}}$ reported significant correlations $(\mathrm{p}<0.05)$ between BMD recorded at ribs, thoracic and LS, pelvis, legs, hip and arms. This study's results are in agreement with others, ${ }^{19} 2930$ although the association between low BMD and fractures has been established in postmenopausal women with osteoporosis ${ }^{59}$ and not in premenopausal.

Generalisations for elite female lightweight rowers are limited by the small sample size, however, lightweight rowing is a 'minority' sport reflected by the relatively small number (79) of female lightweight rowers identified to participate in a national level competition during the study year. Therefore, further research that recruits a larger sample of lightweights and a control group of either non-athletes, athletes from other sports, or nonlightweight rowers is recommended to further substantiate the findings of this study. However, future research should focus on measuring energy input versus energy output and assess in more detail, calcium, antiinflammatory medications, vitamin A and D supplemental intake and the methods and behaviours associated with IWL. The establishment of normal BMD reference ranges in athletes is needed since the application of a reference range based on the general non-athletic population may not be appropriate. ${ }^{17}$ Finally, the effect of upper body resistance and plyometrics training on BMD should be investigated to determine if this could counter the negative effects of $\mathrm{DE}$ and oligomenorrhoea/amenorrhoea.

This study suggests that lightweight rowing rules may be partly responsible for resultant high levels of DE, high rates of oligomenorrhoea/amenorrhoea, BMD deficiencies which are correlated with number of lifetime menses, and the tendency to have DE after retirement. Apparent DE vulnerability of lightweight female rowers beginning training at a younger age is of great concern. Lightweight female rowing rules mean that any athlete above the height of $175 \mathrm{~cm}$ meeting the mean target weight of $57 \mathrm{~kg}$ would be underweight with a BMI of $<18.5$. We would therefore encourage lightweight rowing to embrace sports injury prevention and provide coaches and athletes with appropriate multidisciplinary nutritional and psychological support to prevent DE and the development of the Triad, and perhaps to also consider changing the weight rules to discourage unhealthy weight loss practices. Previous research suggests that rowing performance is strongly correlated to body height (related to arm and leg length), as well as body mass. ${ }^{60-63}$ 
Our study would therefore support competitive categories being explored by height, rather than weight to help avoid detrimental health and performance issues identified in our study related to DE and the Triad.

Contributors LD, AR and RL-S conceived the idea for the study, prepared the methods, collected the data and analysed it, and drafted the initial version of the manuscript. LD completed the scanning and analysed it. RW, AT, LH and $\mathrm{NJ}$ contributed with further critical drafting. All authors critically revised and approved the final version of the manuscript.

Funding This research received no specific grant from any funding agency in the public, commercial or not-for-profit sectors.

Competing interests None.

Ethics approval This study was approved by the Health Studies Ethics Committee at Middlesex University.

Provenance and peer review Not commissioned; externally peer reviewed.

Data sharing statement No additional data are available.

Open Access This is an Open Access article distributed in accordance with the Creative Commons Attribution Non Commercial (CC BY-NC 3.0) license, which permits others to distribute, remix, adapt, build upon this work noncommercially, and license their derivative works on different terms, provided the original work is properly cited and the use is non-commercial. See: http:// creativecommons.org/licenses/by-nc/3.0/

\section{REFERENCES}

1. Rumball JS, Lebrun CM, De Ciacca SR, et al. Rowing injuries. Sports Med 2005;35:537-55.

2. Slater GJ, Rice AJ, Jujika I, et al. Physique traits of lightweight rowers and their relationship to competitive success. Br J Sports Med 2005;39:736-41.

3. Talbott SM, Shapses SA. Fasting and energy intake influence bone turnover in lightweight male rowers. Int J Sport Nutr 1998;8:377-87.

4. Zanker CL, Swaine IL. Relation between bone turnover, oestradiol, and energy balance in women distance runners. $\mathrm{Br} J$ Sports Med 1998;32:167-71.

5. Nattiv A, Loucks AB, Manore MM, et al. American College of Sports Medicine position stand: the female athlete triad. Med Sci Sports Exerc 2007;39:1867-82.

6. Burr DB, Milgrom C. Musculoskeletal fatigue and stress fractures. Boca Raton: CRC Press, 2001.

7. Hoch AZ, Papanek P, Szabo A, et al. Association between the female athlete triad and endothelial dysfunction in dancers. Clin $\mathrm{J}$ Sport Med 2011;21:119-25.

8. Flier JS. Clinical review 94: what's in a name? In search of leptin's physiologic role. J Clin Endocrinol Metab 1998;83:1407-13.

9. Zanker CL, Swaine IL. Responses of bone turnover markers to repeated endurance running in humans under conditions of energy balance or energy restriction. Eur J Appl Physiol 2000;83:434-40.

10. Eriksen EF, Colvard DS, Berg NJ, et al. Evidence of oestrogen receptors in normal human osteoblasts. Science 1988;241:84-6.

11. Ihle R, Louks AB. Dose-response relationships between energy availability and bone turnover in young exercising women. $J$ Bone Miner Res 2004;19:1231-40.

12. Joy EA, Campbell D. Stress fractures in the female athlete. Curr Sports Med Rep 2005;4:323-8.

13. Warren MP, Brooks-Gunn J, Fox RP, et al. Osteopenia in exercise-associated amenorrhea using ballet dancers as a model: a longitudinal study. J Clin Endocrinol Metab 2002;87:3162-8.

14. Hoch AZ, Papanek P, Havlik HS, et al. Prevalence of the female athlete triad/tetrad in professional ballet dancers. Med Sci Sports Exerc 2009; 41:524.

15. Hoch Z, Stavrakos EJ, Schimke FJ. Prevalence of female athlete triad characteristics in a club triathlon team. Arch Phys Med Rehabil 2007;88:681-2.

16. Cobb KL, Bachrach LK, Greendale G, et al. Disordered eating, menstrual irregularity and bone mineral density in female runners. Med Sci Sports Exerc 2003;35:711-19.

17. Pollock P, Grogan C, Perry M, et al. Bone-mineral density and other features of the female athlete triad in elite endurance runners: a longitudinal and cross-sectional observational study. Int J Sport Nutr Exerc Metab 2010;20:418-26.
18. Schtscherbyna A, Soares EA, de Oliveira FP, et al. Female athlete triad in elite swimmers of the city of Rio de Janeiro, Brazil. Nutrition 2009;25:634-9.

19. Warden SJ, Gutschlag FR, Wajswelner $\mathrm{H}$, et al. Aetiology of rib stress fractures in rowers. Sports Med 2002;32:819-36.

20. Nattiv A, Agostini R, Drinkwater B, et al. The female athlete triad: the inter-relatedness of disordered eating, amenorrhea, and osteoporosis. Clin Sports Med 1994;13:405-18.

21. Sundgot-Borgen J, Torstveit MK. Prevalence of eating disorders in elite athletes is higher than in the general population. Clin J Sport Med 2004;14:25-32.

22. Currie A, Morse ED. Eating disorders in athletes: managing the risks. Clin Sports Med 2005;24:871-83.

23. Byrne S, McClean N. Elite athletes: effects of the pressure to be thin. J Sci Med Sport 2002;5:80-94.

24. Terry PC, Lane AM, Warren L. Eating attitudes, body shape perceptions and mood of elite rowers. J Sci Med Sport 1999;2:67-77.

25. Terry PC, Waite J. Eating attitudes and body shape perceptions among elite rowers: effects of age, gender and weight category. Aust J Sci Med Sport 1996;28:3-6.

26. Sundgot-Borgen J. Prevalence of eating disorders in elite female athletes. Int J Sport Nutr 1993;3:29-40.

27. Rauh MJ, Nichols JF, Barrack MT. Relationships among injury and disordered eating, menstrual dysfunction, and low bone mineral density in high school athletes: a prospective study. J Athl Train 2010;45:243-52.

28. Beck TJ, Ruff CB, Shaffer RA, et al. Stress fracture in military recruits: gender differences in muscle and bone susceptibility factors. Bone 2000;27:437-44.

29. Vinther A, Kanstrup IL, Christiansen E, et al. Exercise-induced rib stress fractures: influence of reduced bone mineral density. Scand $J$ Med Sci Sports 2005;15:95-9.

30. Hickey GJ, Fricker PA, McDonald WA. Injuries to elite rowers over a 10-year period. Med Sci Sports Exerc 1997;29:1567-72.

31. Budget R, Hettinga DM, Steinacker J. Sports medicine. In: Secher NH Volianitis S. eds Rowing. London: Blackwell, 2007:124-40.

32. Keen AD, Drinkwater BL. Irreversible bone loss in former amenorrheic athletes. Osteoporosis Int 1997;7:311-15.

33. Barrack MT, Van Loan MD, Rauh MJ, et al. Body mass, training, menses, and bone in adolescent runners: a 3-yr follow-up. Med Sci Sports Exerc 2011;43:959-66.

34. Garner DM, Olmsted MP, Bohr Y, et al. The eating attitudes test: psychometric features and clinical correlates. Psychol Med 1982;12:871-8.

35. American Psychiatric Association. Diagnostic and statistical manual of mental disorders: DSM-IV-TR囚. Washington, DC: American Psychiatric Association, 2000.

36. Karlson KA, Becker CB, Merkur A. Prevalence of eating disordered behaviour in collegiate lightweight women rowers and distance runners. Clin J Sport Med 2001:11:32-7.

37. Sundgot-Borgen J. Risk and trigger factors for the development of eating disorders in female elite athletes. Med Sci Sports Exerc 1994;26:414-19.

38. Smolak L, Murnen SK, Ruble AE. Female athletes and eating problems: a meta-analysis. Int J Eat Disord 2000;27:371-80.

39. Martinsen M, Sundgot-Borgen J. Higher prevalence of eating disorders among adolescent elite athletes than controls. Med Sci Sports Exerc 2013;45:1188-97.

40. Thiel A, Gottfried H, Hesse FW. Subclinical eating disorders in male athletes: a study of the low weight category in rowers and wrestlers. Acta Psychiatr Scand 1993;88:259-65.

41. Beals KA, Manore MM. Behavioral, psychological, and physical characteristics of female athletes with subclinical eating disorders. Int J Sport Nutr Exerc Metab 2000;10:128-43.

42. Sundgot-Borgen J, Klungland $\mathrm{M}$. The female athlete triad and the effect of preventative work. Med Sci Sports Exerc 1998;30:S181.

43. Emery CA, Hagel B, Morrongiello B. Injury prevention in child and adolescent sport: whose responsibility is it? Clin J Sport Med 2006;6:514-21.

44. Carney CP, Andersen AE. Eating disorders. Guide to medical evaluation and complications. Psychiatr Clin North Am 1996;19:657-79.

45. Smock AJ, Hughes JM, Popp KL, et al. Bone volumetric density, geometry and strength in female and male collegiate runners. Med Sci Sports Exerc 2009;41:2026-32.

46. Drinkwater $\mathrm{BL}$, Nilson $\mathrm{K}$, Chesnut $\mathrm{CH}$ III, et al Bone mineral content of amenorrheic and eumenorrheic athletes. $N$ Engl J Med 1984;2:277-81

47. Lariviere JA, Robinson TL, Snow CM. Spine bone mineral density increases in experienced but not novice collegiate female rowers. Med Sci Sports Exerc 2003;35:1740-4. 
48. Wolman RL, Clark P, McNally E, et al. Menstrual state and exercise as determinants of spinal trabecular bone density in female athletes. BMJ 1990;301:516-18.

49. Gee TI, Olsen PD, Berger NJ, et al. Strength and conditioning practices in rowing. J Strength Cond Res 2011;25:668-82.

50. Ivey P, Oakley J, Hagerman P. Strength training for the preparatory phase in collegiate women's rowing. Strength Cond J 2004;26:10-15

51. Ebben WP, Kindler AG, Chirdon KA, et al. The effect of high-load vs. high-repetition training on endurance performance. J Strength Cond Res 2004;18:513-17.

52. Nevill AM, Burrows M, Holder RL, et al. Does lower-body BMD develop at the expense of upper-body BMD in female runners? Med Sci Sports Exerc 2003;35:1733-9.

53. Manore MM. Dietary recommendations and athletic menstrual dysfunction. Sports Med 2002;32:887-901.

54. Kohrt WM, Ehsani AA, Birge SJ Jr. Effects of exercise involving predominantly either joint-reaction or ground-reaction forces on bone mineral density in older women. J Bone Miner Res 1997;12:1253-61.

55. Sanchis-Moysi J, Dorado C, Olmedillas $\mathrm{H}$, et al. Bone and lean mass inter-arm asymmetries in young male tennis players depend on training frequency. Eur J Appl Physiol 2010;110:83-90.
56. Platen $\mathrm{P}$, Chae $\mathrm{EH}$, Antz $\mathrm{R}$, et al. Bone mineral density in top level male athletes of different sports. Eur J Sport Sci 2001;1:1-15.

57. Strayer LM. The myth of the intercostal muscle pull. Am Rowing 1990;22:42-4.

58. Øyen J, Torstveit MK, Sundgot-Borgen J. Self-reported versus diagnosed stress fractures in Norwegian female elite athletes. $J$ Sports Sci Med 2009;8:130-5.

59. Melton LJ III, Atkinson EJ, O'Fallon WM, et al. Long-term fracture prediction by bone mineral assessed at different skeletal sites. J Bone Miner Res 1993;8:1227-33.

60. Yoshiga CC, Higuchi M. Rowing performance of female and male rowers. Scand J Med Sci Sports 2003;13:317-21.

61. Barrett RS, Manning JM. Rowing: relationships between rigging set-up, anthropometry, physical capacity, rowing kinematics and rowing performance. Sports Biomech 2004;3:221-35.

62. Chun-Jung, Huang, Thomas W, Nesser TW, et al. Strength and power determinants of rowing performance. J Exerc Physiol Online 2007;10:43-50.

63. Pavle M, Ružić L. Predicting the $1000 \mathrm{~m}$ rowing ergometer performance in 12-13-year-old rowers: the basis for selection process? J Sci Med Sport 2008:11:218-26. 